\title{
Las sociedades latinoamericanas complejas y el nuevo proceso de constitucionalización
}

\section{Complex Latin American societies and the new constitutionalization process}

\section{Sociedades latino-americanas complexas e o novo processo de constitucionalização}

\author{
Dr. Luis Meliante Garcé
}

Prof. Adj. efectivo de Filosofía y Teoría General del Derecho; Prof. Tit. de Filosofía y Teoría General del Derecho, Facultad de Derecho, Universidad Claeh. Contacto: luimelgar@ hotmail.com

\section{Resumen}

Las sociedades contemporáneas latinoamericanas, más allá de la conocida tradición del constitucionalismo latinoamericano, en su complejo presente muestran, a grandes rasgos, por un lado, constituciones que responden claramente a la tradición europea de posguerra (México, Argentina, Uruguay, Colombia) y, por otro, aquellas que lo hacen respecto del denominado nuevo constitucionalismo latinoamericano, una nueva corriente cuya características principales serán aquí analizadas y que se consolida en Ecuador (2008) y Bolivia (2009), como años antes (1999) lo hiciera también en Venezuela.

Sin perjuicio de ello, también han tenido cierto arraigo en la región algunos ecos traslaticios del autodenominado neoconstitucionalismo eurocéntrico. Es probable que esta corriente tenga serias aspiraciones a convertirse en una suerte de teoría del derecho más que en una teoría de la Constitución, y muchas veces se aparta de la nueva teoría constitucionalista latinoamericana, aunque, paradojalmente, en muchos aspectos también mira hacia el mismo lado que aquella.

En este trabajo se pretende - entre otros objetivos- aclarar estas afirmaciones y hacer referencia a las particularidades más relevantes de cada una de sus versiones, con la intención de posibilitar una sana discusión de sus contenidos.

Palabras clave: sociedades complejas, Latinoamérica, constitucionalización, poder, neoconstitucionalismo, nuevo constitucionalismo. 


\begin{abstract}
Contemporary Latin American societies, beyond the well-known tradition of Latin American constitutionalism, clearly show that, in their present complex, they show, on the one hand, constitutions that clearly respond to the post-war European tradition (Mexico, Argentina, Uruguay, Colombia, among others), and on the other hand those that do with the so-called new Latin American constitutionalism, a new current, whose main characteristics will be analyzed and consolidated in Ecuador (2008), Bolivia (2009) and a few years earlier, in Venezuela (1999).

Notwithstanding this, some transference echoes towards the region, of the self-styled Eurocentric neo-constitutionalism, have also had some roots. This current, is likely to have serious aspirations to become a kind of Theory of Law rather than a Theory of the Constitution and often departs from the new Latin American constitutional theory, although paradoxically, in many aspects, also looks towards the same aside that one.

In this work, it is intended - among other aspects - to clarify this statement and make reference to the most relevant particularities of each of the versions, with the intention of enabling a healthy discussion of its contents.
\end{abstract}

Keywords: Complex societies, Latin America, constitutionalization, power, neo-constitutionalism, new constitutionalism.

\title{
Resumo
}

As sociedades latino-americanas contemporâneas, além da bem conhecida tradição do constitucionalismo latino-americano, mostram claramente que, em seu complexo atual, mostram, por um lado, constituições que respondem claramente à tradição européia do pós-guerra (México, Argentina, Uruguai, Colômbia, entre outros), e por outro lado, aqueles que fazem com o chamado novo constitucionalismo latino-americano, uma nova corrente, cujas principais características serão analisadas e consolidadas no Equador (2008), Bolívia (2009) e alguns anos antes, na Venezuela (1999).

Não obstante, alguns ecos de transferência para a região, do autoconstituído neoconstitucionalismo eurocêntrico, também tiveram algumas raízes. Essa corrente provavelmente terá sérias aspirações de se tornar uma espécie de Teoria do Direito, em vez de uma Teoria da Constituição, e muitas vezes se afasta da nova teoria constitucional latino-americana, embora paradoxalmente, em muitos aspectos, também olha na mesma direção. Deixando isso de lado.

Neste trabalho, pretende-se - entre outros aspectos- esclarecer essa afirmação e fazer referência às particularidades mais relevantes de cada uma das versões, com a intenção de possibilitar uma discussão saudável de seu conteúdo.

Palavras-chave: sociedades complexas, América Latina, constitucionalização, poder, neoconstitucionalismo, novo constitucionalismo. 


\section{Introducción}

De manera breve, puede decirse que las formas para que una sociedad pueda calificarse como compleja son muchas; estas se evidencian cuando se pretende analizar los límites de una organización social —los «límites de sentido» a los que aludía Luhmann (1975)—,1 por lo que debe tomarse en cuenta que la complejidad se percibe tanto desde dentro de la organización como desde fuera de ella.

Recordemos que para Luhmann, la complejidad del entorno - exterior - debe ser aprendida por el sistema social para que este pueda reducir su porción, para que genere complejidad al propio sistema. Por su parte, Habermas entendía que en los sistemas sociales existen dos fuentes de complejidad que pueden estar relacionadas: la primera es la complejidad que proviene del ambiente, la que se aprende y reduce a través de la definición de sentido propuesta por Luhmann; la segunda, la complejidad que proviene del propio sistema, lo que puede percibirse en función de las dificultades en los sistemas sociales propias de estos para adaptarse a cambios repentinos en su ambiente.

A ello debe agregarse, sin duda, la percepción de la complejidad a partir de los sujetos que, en definitiva, son parte constitutiva esencial de todos los sistemas y subsistemas sociales.

De hecho, toda sociedad compleja se caracteriza básicamente por una diferenciación funcional nítida entre los sistemas y subsistemas parciales que la componen y que apuntan a una creciente autonomía; una radical división del trabajo mediante la especialización y capitalización del conocimiento por sujetos y grupos sociales; una diversificación económica sujeta a las turbulencias globales, junto con el surgimiento de nuevas formas de institucionalización jurídico-políticas, y un acentuado proceso de comunicación.

En este último sentido, muchas de las formaciones sociales latinoamericanas del denominado horizonte cultural latinoamericano (Cobos, 1995; Meliante, 2014) ${ }^{2}$ se ven enfrentadas a distintas situaciones histórico-sociales vinculadas a nuevas formas de distribución del poder, lo que trae aparejado una innegable repercusión en el subsistema jurídico-político.

Se verá a continuación este aspecto, en particular desde los marcos en que se puede configurar a partir de las mutaciones que afectan libremente las distintas formas de construcción constitucional, naturalmente autopoiéticas.

\section{Una representación no distópica de una sociedad compleja en Latinoamérica}

Los fuertes reclamos de justicia social e igualdad, así como las pretensiones de transparencia en la gestión de las autoridades públicas que repercuten también en la administración de justicia, son producto, en general, de fuertes oposiciones entre grupos sociales con distintas formas de hegemonía y consistencia, y cuya conformación y posicionamiento en la estructura social dependen de factores de diferente

ANUARIO DEL ÁREA SOCIO-JURÍDICA | MONTEVIDEO - URUGUAY | v. 10 | n. 1 | p. 32-49 | DEZ. 2018 
naturaleza: económicos, sociales, políticos y culturales en sentido amplio. Tal situación deja percibir sobre esa matriz una complejidad creciente, a la vez que una polarización social también en aumento.

Uruguay no escapa a estas características, y es conveniente destacar que tan solo cuatro décadas atrás - poco más - era imposible ponderar desde el punto de vista jurídico la consideración teórica de estos aspectos porque, entre otras causas, además de la incidencia negativa de los oscuros años dictatoriales, también es probable que tales temas fueran ajenos al interés primordial de la mayoría de los juristas.

Esta breve y limitada puesta en escena muestra algunas de sus muy complejas aristas, las que afectan en particular el derecho latinoamericano contemporáneo e inciden de manera notoria en una de sus ramas: el derecho público. Decirlo así es una de las tantas maneras posibles de justificar el abordaje del tema que se ha propuesto, y así evitar que quede atrapado en un encuadre meramente formal y quizás exclusivamente descriptivo, sin que se muestre la conflictividad que anida en su interior.

De tal manera, el trabajo que sigue, en sus notas principales, trata de ello para que sirva como escenario válido donde analizar también las formas de los procesos constituyentes latinoamericanos más recientes. Sin eludir una perspectiva diacrónica, constituirá este el núcleo más importante de la temática que se aborda.

\section{El constitucionalismo latinoamericano y la distribución del poder. Breve consideración en un corte diacrónico}

Toda organización política de una sociedad requiere un conjunto de normas para funcionar, pero no todo conjunto de normas puede tomar el carácter de organización constitucional (Salazar Ugarte, 2012:346). En particular, ese conjunto de normas debe conceder un conjunto de derechos fundamentales.

Es claro que el constitucionalismo de corte democrático, en su forma articulada y codificada en un texto denominado Constitución, es un producto político de las revoluciones liberales acaecidas en Estados Unidos y Francia, a fines del siglo XVIII, cuyo contenido recoge la filosofía contractualista que naciera en el siglo precedente. Pone en escena, por un lado, un poder constituyente absoluto e ilimitado, en cuanto prejurídico; por otro, un poder constituido, posjurídico y constitucionalmente limitado. Su necesidad primordial, producto de la herencia revolucionaria, fue entonces organizar una forma de distribución del poder limitado a través de la Constitución. Ya en el siglo XIX, la consumación constituyente en Latinoamérica consolida la tradición constitucional del siglo anterior e inaugura una forma de constitucionalismo que puede llamarse latinoamericano, que recoge versiones heterogéneas con influencias provenientes del constitucionalismo estadounidense y francés, por supuesto, y que arroja productos diferentes, aunque en algunos aspectos similares, como fueron los sistemas constitucionales instaurados en México, Venezuela, Colombia, Brasil, Argentina y Uruguay, donde fue notoria la influencia jurídica de la corriente iusnaturalista del derecho.

Bobbio, en el siglo XX, estimaba que en las constituciones de tradición liberal debían consignarse las cuatro libertades de los modernos: personal, de pensamiento, de reunión y de asociación. Si el documento

ANUARIO DEL ÁREA SOCIO-JURÍDICA | MONTEVIDEO - URUGUAY | v. 10 | n. 1 | p. 32-49 | DEZ. 2018 
constitucional, que en esta tradición debe ser rígido, escrito y supremo, contenía además derechos políticos, podía hablarse de constitucionalismo democrático; si contemplaba derechos sociales, podía hablarse de constitucionalismo social, y si contenía todos esos derechos, podíamos hablar de constitucionalismo democrático y social de derecho. A ello debe agregarse una necesaria garantía para poder gozar de esos derechos que se conceden, y además, una clara división de poderes que garantice los principios de legalidad, igualdad e imparcialidad judicial (Salazar Ugarte, 2012:347).

Sin perjuicio de estas consideraciones que sucintamente se exponen, ubicándonos en la tradición liberal occidental y con referencia al constitucionalismo democrático que surgiera en Europa sobre la mitad del siglo XX, luego de la segunda guerra mundial, Salazar Ugarte (2012:347) agrega a las características reseñadas en el párrafo anterior otras tales como un elenco relevante de derechos fundamentales (libertades, derechos políticos, sociales), reglas que organicen el acceso democrático al poder político y mecanismos de control constitucional sobre las leyes.

Con relación a Latinoamérica, más allá de la conocida tradición del denominado constitucionalismo latinoamericano a que ya se aludiera, es claro que en su presente, nuestro horizonte cultural muestra hoy, a grandes rasgos, por un lado, constituciones que responden a la tradición europea de posguerra (México, Argentina, Uruguay, Colombia), y por otro, constituciones que responden al denominado nuevo constitucionalismo latinoamericano como nueva corriente cuyas características principales veremos más adelante y que se consolida en Ecuador (2008) y Bolivia (2009), como años antes (1999) lo hiciera en Venezuela.

\section{Latinoamérica. El panorama del constitucionalismo: entre neo eurocéntrico y nuevo latinoamericano}

En el discurso teórico contemporáneo acerca del derecho ya casi es lugar común la referencia a su proceso de constitucionalización. Este puede ser visto desde su matriz eurocéntrica, sobre todo a través de la corriente neoconstitucionalista, de larga tradición y emergente en la segunda posguerra, o desde aquella otra con peculiaridades latinoamericanas, como en el llamado nuevo constitucionalismo latinoamericano, cuyo primer aspecto diferencial de la primera óptica radica en proponer para las nuevas constituciones latinoamericanas lo que se ha dado en llamar un "poder negativo como forma diversa de ejercicio directo o indirecto de la soberanía por parte del pueblo» (Noguera Fernández, 2011:180-181), instrumento tendiente a sostener su voluntad constituyente a través del control de constitucionalidad contra cualquier forma de intento de subversión, incluso la de aquellos constitucionalmente habilitados para ejercer el poder.

Con esta forma de constitucionalismo se procura, según se ha dicho, «disminuir la clásica contradicción entre justicia constitucional y democracia» (Noguera Fernández, 2011:195).

Se comenzó también a otorgar otra dimensión y analizar con mayor cuidado el rol de los jueces dentro del Estado, adjudicándoles de alguna manera la función de gestores del control de calidad de las

ANUARIO DEL ÁREA SOCIO-JURÍDICA | MONTEVIDEO - URUGUAY | v. 10 | n. 1 | p. 32-49 | DEZ. 2018 
decisiones políticas, para con ello lograr una mayor apuesta a la forma, el contenido y el alcance de las decisiones judiciales (Meliante, 2014:176-177).

Asimismo, tanto el desarrollo del neoconstitucionalismo eurocéntrico — si se quiere, mejor dicho, el contemporáneo constitucionalismo europeo - como la nueva teoría latinoamericana pujan por la ponderación del concepto de tutela judicial efectiva como forma de garantizar la vigencia de los derechos humanos frente a la posible opacidad o - incluso- insuficiencia de su producción legislativa en sentido amplio. Esto ha llevado a que los órganos encargados del control de constitucionalidad produzcan decisiones con un alcance diferente al que tradicionalmente han generado.

Se les ha denominado por la doctrina especializada (Nogueira de Alcalá, 2004) sentencias atípicas, ${ }^{3}$ y constituyen en general instrumentos que, de alguna manera, vuelven operativos valores y principios constitucionales, desarrollan su fuerza constitucional y garantizan una adecuación del ordenamiento infraconstitucional a la Constitución cuando se vulneran derechos fundamentales; evitan también situaciones de inconstitucionalidad, a través de la aplicación de simples sentencias estimatorias de inconstitucionalidad (Nogueira de Alcalá, 2004:87-88).

Puede ser que este tema no ofrezca demasiadas aristas para posibles cuestionamientos cuando el control de constitucionalidad se ejerce por tribunales constitucionales estrictu sensu. Pero sucede que el empuje neoconstitucionalista eurocéntrico —el que se ha desplegado con mayor fuerza en Uruguay, por ejemplo, a cuestas de algunas calificadas interpretaciones (Guariglia, 2009; Durán Martínez, 2012; Gamarra, 2012; Leiza Zunino, 2016) - puede propiciar la irrupción de situaciones inéditas, en cuanto alienta a la Judicatura de primera instancia a que en forma motivada active, mediante los procedimientos naturales del subsistema jurídico procesal, la desaplicación de la legislación infraconstitucional cuando se estime que esta contradice principios integrados al bloque de constitucionalidad programático de protección de los derechos fundamentales —en el caso de Uruguay, nos referimos a los artículos, 7, 72 y 332 de la Constitución, básicamente - o incluso más, en cuanto pueda contradecir principios generales de máximo valor y fuerza que campean en forma supraconstitucional y que son inherentes a un orden jurídico con validez y reconocimiento universal que debe primar aun por sobre el orden constitucional supralegal.

Ahora bien, el neoconstitucionalismo -o constitucionalismo actual, como en realidad debería llamarse, según la conocida opinión de Comanducci (2002) - tiene distintas perspectivas: ideológica, metodológica, etc. Es común a todas ellas un discurso tendiente al desplazamiento del principio de primacía de la ley, que se ve sobrepujado por el de primacía de la Constitución, y, como ya vimos, un estímulo a toda la Judicatura para instituirse en controladora de la constitucionalidad de la legalidad total y de la actuación de las autoridades estatales, particularmente.

De esta manera, como puede verse, por golpe de baranda, se legitima también sobre bases teóricas específicas la posibilidad de politización de la justicia.

Pero veamos de manera un poco más profunda los aspectos sustanciales de las dos corrientes que hemos venido considerando.

Ferrajoli distingue dos modelos de Estado de derecho surgidos luego de la vigencia del paradigma de derecho jurisprudencial premoderno, identificado con los principios de derecho natural y que, según el autor, puede situarse en el ancien regime, a saber: a) el paleoiuspositivista, de Estado legislativo de

ANUARIO DEL ÁREA SOCIO-JURÍDICA | MONTEVIDEO - URUGUAY | v. 10 | n. 1 | p. 32-49 | DEZ. 2018 
derecho (Estado legal), y $b$ ) el neoiusposivista, de Estado constitucional de derecho (Estado constitucional), este último resultante de un modelo difundido en Europa tras la segunda guerra mundial y caracterizado por ser producto de cartas constitucionales rígidas y ponderación del control de constitucionalidad de las leyes ordinarias. El autor ha sugerido también que quizá nos encontremos ante un tercer modelo posible de Estado de derecho (Ferrajoli, 2002:8-9).

Probablemente se pueda afirmar, como se ha hecho en la doctrina publicista española (Viciano Pastor y Martínez Dalmau, 2010:3), que este empuje neoconstitucionalista europeo «se aleja de los esquemas del positivismo teórico» y utiliza la presencia hegemónica de los «principios generales del derecho» como criterios de interpretación, lo que ha constituido la principal herramienta de ataque al positivismo jurídico, aspirando a conceder a través de tales «principios generales» la «unidad material» del sistema jurídico, aunque se encuentren presididos por el pluralismo (Sastre Ariza, cit. por Viciano Pastor y Martínez Dalmau, 2010:3).

Esta versión eurocéntrica se caracteriza también por promover una Constitución invasora, por positivizar un vasto catálogo de derechos, por justificar la presencia textual de principios y por la aplicación de normas constitucionales respecto de la interpretación y aplicación de la ley (Viciano Pastor y Martínez Dalmau, 2010:3). Como veremos más adelante, estas características no son exclusivas de esta corriente.

\section{La gestación de los distintos constitucionalismos en sus versiones neo eurocéntrico y nuevo latinoamericano. Divergencias y coincidencias. La sobreinterpretación constitucional}

Según explican Viciano Pastor y Martínez Dalmau, la versión europea neo del constitucionalismo es una corriente doctrinal que tiene el arraigo de años de teorización académica y en forma trascedente desde fines de la segunda guerra mundial. Por su parte, el nuevo constitucionalismo latinoamericano es un producto no ya de la academia, sino surgido desde las reivindicaciones de los movimientos sociales y, como veremos seguidamente, carece de la necesaria cohesión y articulación como sistema cerrado de análisis y proposición de un modelo constitucional (Viciano Pastor y Martínez Dalmau, 2010:3-4).

No obstante, si hay una consigna explícita e implícita en la que coinciden ambas versiones, se encuentra en la necesaria constitucionalización del ordenamiento jurídico, proyectando una evolución hacia una fase nueva de Estado: el Estado constitucional de derecho; hacia allí deben dirigirse todos los esfuerzos teóricos. Este aspecto es destacado por los autores citados cuando señalan que se releva en el nuevo constitucionalismo latinoamericano una preocupación referida «no tanto a la dimensión jurídica de la Constitución, sino primero a la legitimidad democrática de la misma» (Viciano Pastor y Martínez Dalmau, 2010:4).

El problema principal se sitúa así en reflejar

ANUARIO DEL ÁREA SOCIO-JURÍDICA | MONTEVIDEO - URUGUAY | v. 10 | n. 1 | p. 32-49 | DEZ. 2018 
una traslación fiel de la voluntad constituyente y establecer los mecanismos de relación entre la soberanía, esencia del poder constituyente, y la Constitución entendida en su sentido amplio como la fuente del poder (constituido y, por lo tanto, limitado) que se superpone al resto del derecho y a las relaciones políticas y sociales. (Viciano Pastor y Martínez Dalmau, 2010:4)

Según los autores citados, la versión del nuevo constitucionalismo latinoamericano busca analizar, en primer lugar, la exterioridad de la Constitución, lo que no es otra cosa que su legitimidad, que por su naturaleza es extrajurídica, para luego analizar su interioridad, con referencia a su normatividad; en este último aspecto existirían conexiones con la versión neoconstitucionalista eurocéntrica.

En la nueva versión latinoamericana que se está analizando, el Estado constitucional solo puede ser aquel regido por una Constitución legitimada democráticamente por el poder constituyente (Guastini, 2001:40), que refleja su voluntad y rige sin excepciones las relaciones jurídicas y políticas creadas a partir de ella (Viciano Pastor y Martínez Dalmau, 2010:5).

El tema referido al concepto de poder constituyente no es simple. Se distingue en general la noción de poder constituyente de aquella de poder constituido. Este último es aquel poder constitucional y legalmente estatuido y regulado a partir de una Constitución y, en particular, en opinión de Guastini, desde la primera Constitución del Estado; el poder constituyente, en su opinión, es el que instaura la primera Constitución. En esta visión positivista, el poder constituyente, despejado de ideología, dice el autor, no es fundamento axiológico de la Constitución: es el hecho que da nacimiento a la primera Constitución; pero no le sobrevive, sino que desaparece con ella y en ella.

Por el contrario, en la visión de las constituciones que recogen el nuevo consitucionalismo latinoamericano, podrá coincidirse en parte con la visión de Guastini acerca del poder constituido. En cambio, el poder constituyente no fenece: permanecería vivo y activo.

Ahora bien, de acuerdo a lo expresado, parece ser que la versión eurocéntrica, por su parte, pretende transformarse en una teoría del derecho (Viciano Pastor y Martínez Dalmau, 2010:5), en función de esta característica de pretender impregnar todo el ordenamiento jurídico de normas constitucionales que, según advierte Guastini (2001:153), se caracterizan por una Constitución invasora, como ya se viera, capaz de condicionar tanto la legislación como la jurisprudencia y el estilo doctrinal.

La respetada opinión de Guastini puede generar alguna interrogante y, a su vez, la necesidad de encontrar para ello una explicación.

En efecto, este aspecto de establecer como una de las características del constitucionalismo la peculiaridad invasiva de la Constitución ha sido primero ideológicamente aceptada por la versión del constitucionalismo eurocéntrico; luego, de alguna manera, se ha trasladado al nuevo constitucionalismo latinoamericano. No obstante, podríamos llegar a preguntarnos, sin que ello constituya una falacia, cómo debería entenderse esta característica o condición de una Constitución invasora de la legalidad propuesta por Guastini si precisamente las leyes — normas abstractas, generales y obligatorias—, válidas y eficaces aun en el más tenue y el más rígido positivismo, acomodan su condición a la propia Constitución. ¿Será que esta característica invasiva de la Constitución supone otorgar contenidos normativos de corte legal a las disposiciones constitucionales, incluso aquellas meramente programáticas? ¿Será que a cuestas de la sobreinterpretación constitucional, al no quedar, como el propio autor expresa, «espacios vacíos de —o

ANUARIO DEL ÁREA SOCIO-JURÍDICA | MONTEVIDEO - URUGUAY | v. 10 | n. 1 | p. 32-49 | DEZ. 2018 
sea, «libres» del- derecho constitucional, toda decisión legislativa está prerregulada — quizás aun minuciosamente regulada - por una u otra norma constitucional[?] No existe ley que pueda escapar al control de legitimidad constitucional» (Guastini, 2001:159-160). Sea como sea, esta invasión proyectada y promovida desde el sistema constitucional se irradia a todo el sistema infraconstitucional sin que exista un resquicio que quede libre de ella. Y tal expansión abarca no solo los espacios propios de su cometido organización política, distribución del poder, derechos fundamentales, etc.-, sino también el derecho privado en general. Se reafirmaría así la pretensión del neoconstitucionalismo eurocéntrico de consolidarse como una nueva teoría de todo el derecho

Así las cosas, en principio, el atractivo de la propuesta no evita la generación de interrogantes nada estériles.

Por su parte, la versión latinoamericana será teoría del derecho solo subsidiariamente, y tan solo en la medida en que la Constitución rige el resto del ordenamiento jurídico; pero según los autores citados, es, sí, básicamente, una teoría democrática de la Constitución (Viciano Pastor y Martínez Dalmau, 2010:5).

Esta teoría se ha convertido, según nuestros autores, en práctica a partir de nuevos procesos constituyentes dados en algunos lugares de Latinoamérica donde se han legitimado textos constitucionales que han buscado reflejar la voluntad del poder constituyente, penetrar en el ordenamiento jurídico y modificar en profundidad el statu quo de sociedades en estado de necesidad, avanzando por el camino de la justicia social, la igualdad y el bienestar de los ciudadanos (Viciano Pastor y Martínez Dalmau, 2010:5). En similares apreciaciones a este respecto coinciden los profesores argentinos Gargarella y Courtis (2009:11).

Los procesos constitucionales latinoamericanos a los que se ha hecho referencia son, de alguna manera, resultado directo de los conflictos sociales que aparecieron durante la aplicación de políticas neoliberales, en particular en la década del ochenta del siglo pasado, y de los movimientos populares que intentaron contrarrestarlos (Viciano Pastor y Martínez Dalmau, 2010:6). Es decir que por razones vinculadas con necesidades sociales y deficiencias en la instalación democrática, los nuevos procesos constituyentes latinoamericanos toman fuerza a partir de la década de los años noventa del siglo precedente (puede señalarse a Colombia como antecedente válido en este sentido; Viciano Pastor y Martínez Dalmau, 2010:9).

Según explica Salazar Ugarte, en el nuevo constitucionalismo latinoamericano, las constituciones que lo acompañan comparten una vocación social que se traduce en el reconocimiento de derechos orientados hacia el combate a la exclusión y la desigualdad, y amplios capítulos económicos para garantizar la participación del Estado en las «decisiones públicas sobre los recursos naturales o la regulación de la actividad financiera» (Salazar Ugarte, 2012:356).

Si bien efectuar un breve análisis de los procesos constituyentes que se toman en general como referentes del nuevo constitucionalismo latinoamericano excede ampliamente los límites y objetivos propuestos para este trabajo - incluso por razones de especialidad-, es del caso mencionar tan solo que en este enclave suelen considerarse los procesos constituyentes de Ecuador, Bolivia y Venezuela, que con intermitencias y relecturas se consolidaron en su última fase durante el presente siglo.

ANUARIO DEL ÁREA SOCIO-JURÍDICA | MONTEVIDEO - URUGUAY | v. 10 | n. 1 | p. 32-49 | DEZ. 2018 
Según afirman los autores citados, las experiencias constituyentes de estos países se conforman en sí mismas como un modelo teórico-práctico de proceso constituyente (Viciano Pastor y Martínez Dalmau, 2010:11).

De esta manera se señalan como elementos formales comunes al nuevo constitucionalismo latinoamericano el de legitimidad y el de necesidad. Al primero ya se hizo referencia, en busca de la recuperación de la teoría clásica de los procesos constituyentes y la naturaleza originaria y creadora del poder constituyente, todo ello enmarcado en el concepto racional-normativo de Constitución como texto escrito, ordenado y articulado, aunque adentrándose en el fortalecimiento de su dimensión política (Viciano Pastor y Martínez Dalmau, 2010:12). El segundo se orienta hacia la búsqueda de elementos útiles para el cambio de objetivos planteados por el proceso constituyente, aspecto en el que se percibe la insistencia de incorporar al texto constitucional conceptos e instituciones que coadyuven con su aplicación en el cumplimiento de la Constitución, así como en la mejora de la calidad y condiciones de vida de los ciudadanos. Para ello se rompe incluso con el poder de reforma del texto constitucional colocado en manos de legislativos ordinarios, tal como provenía del constitucionalismo liberal tradicional, dejándose de lado así el hecho de que la capacidad de reforma quede en manos de poderes constituidos para trasladarla a un poder constituyente que radica en la soberanía popular.

Se trasluce también la incorporación de un lenguaje simbólico que debe relacionarse con el fortalecimiento de la dimensión política de los referidos Estados más que con previsiones de índole jurídica. En este sentido, por ejemplo, los autores referidos hablan de «República Bolivariana de Venezuela» en lugar de «República de Venezuela», y de «Estado Plurinacional de Bolivia», en sustitución de «República de Bolivia».

En suma, deben señalarse como características propias de este nuevo constitucionalismo los siguientes elementos: $a$ ) un contenido innovador (originalidad), $b$ ) una relevante extensión del articulado (amplitud), c) una capacidad de conjugar elementos técnicos complejos con un lenguaje accesible (complejidad) y $d$ ) la ponderación del poder constituyente que radica en el pueblo ante cualquier posibilidad de cambio constitucional, lo que denota una clara rigidez en estos textos constitucionales (Viciano Pastor y Martínez Dalmau, 2010:14). Las características principales de este concepto de rigidez constitucional sucintamente enunciadas pueden resumirse en estos dos rasgos: estabilidad, en tanto la rigidez asegura la perdurabilidad de la Constitución en la medida en que los cambios que se proyecten solo podrán ser logrados luego de un largo proceso de discusión, y definitividad, en la medida en que la Constitución rígida impone por principio un límite al accionar legislativo (Burstin, Sarlo et al., 2010:17 y ss.).

Quizás una de las peculiaridades que denotan los nuevos textos que surgen de los procesos constitucionales ya referidos y que se insertan en el marco del nuevo constitucionalismo latinoamericano sea que se trata de textos principistas, ${ }^{4}$ en lo que tiene que ver con los criterios de interpretación, en especial cuando estos criterios que toman como fuente a determinados principios generales se dirigen a los tribunales constitucionales para generar un razonamiento vinculante al momento de interpretar el texto constitucional (Viciano Pastor y Martínez Dalmau, 2010:15). Debe señalarse también como aspecto original que, en general, las constituciones emanadas de los nuevos procesos constituyentes latinoamericanos a que hemos hecho referencia plantean, teniendo en cuenta sus respectivas realidades

ANUARIO DEL ÁREA SOCIO-JURÍDICA | MONTEVIDEO - URUGUAY | v. 10 | n. 1 | p. 32-49 | DEZ. 2018 
nacionales, la integración de sectores tradicionalmente marginados, como los pueblos indígenas, lo que es notorio en la Constitución del Estado Plurinacional de Bolivia al reconocer la autonomía indígena así como su jurisdicción, sin relación de subordinación con la jurisdicción ordinaria, además de un amplio espectro de derechos referidos de manera específica a estos pueblos originarios y el reconocimiento de derechos vinculados a las formas electivas de sus representantes, potenciado todo con la integración de la jurisdicción indígena al Tribunal Constitucional. 5

También es correcto mencionar que los nuevos textos de esta variante del constitucionalismo prevén la introducción de mecanismos de participación ciudadana directa en la elección de los miembros de los tribunales constitucionales, ${ }^{6}$ aspecto radical en el caso de Bolivia y más atenuada en los casos de Ecuador y Venezuela.

Esta cuestión introduce un tópico de discusión en el propio terreno del nuevo constitucionalismo latinoamericano, como bien lo plantea Salazar Ugarte.

En efecto, como ya se ha considerado brevemente, esta visión del constitucionalismo responde a una génesis y una vocación declaradamente popular inspirada en principios de democracia radical. Entendemos que esta condición, conforme a los elementos que surgen de las nuevas constituciones latinoamericanas, estaría plasmada en función de dos criterios que dan cuenta de mecanismos de poder negativo indirecto, es decir, formas de democratización del control de constitucionalidad y formas de ejercicio directo de la soberanía popular tendientes a sostener su voluntad constituyente: $a$ ) uno jurisdiccional, que contempla la legitimación activa que corresponde a cualquier ciudadano para interponer recursos de inconstitucionalidad ante cualquier acto de poder como forma de respeto de la voluntad constituyente (Noguera Fernández, 2011:182-184),7 así como las acciones consagradas para que los ciudadanos puedan atacar la vulneración por omisión de la Constitución por parte de los poderes públicos, ${ }^{8}$ y b) otro institucional, que rompe la tradicional tripartición de poderes con el sistema de autocontrol de pesos y contrapesos entre los tradicionales poderes del Estado, fusionado con el paradigma de la democracia representativa parlamentaria como forma de ejercicio del poder. Frente a esta forma tradicional se crea un tipo de poder popular autónomo, con capacidad de ejercer control democrático y poder negativo sobre los gobernantes (Noguera Fernández, 2011:187-189). Es así que se rompe la estructura tripartita del poder para dar paso, además de los tres poderes tradicionales (Ejecutivo, Legislativo y Judicial), al Poder Electoral y al Poder Ciudadano de Control (Venezuela, 1999, título V, capítulo IV), al Poder de Transparencia y Control Social (Ecuador, 2008, capítulo V, título IV) o al de Participación y Control Social (Bolivia, 2009, artículos 241 y 242).

No obstante, esta misma vocación popular, la extensión de los textos constitucionales y su lenguaje simbólico reseñado líneas atrás, el contenido principista y la complejidad interpretativa colocan potencialmente a los jueces como intérpretes únicos, controladores y custodios de la vigencia de las constituciones no solo desde el punto de vista jurídico, sino también político (Salazar Ugarte, 2012:377). Los jueces pueden, así, apropiarse del contenido constitucional e imponer su voluntad al resto de los poderes constituidos, así como a todo el sistema político. Para ello, en estos nuevos textos, los jueces cuentan con un amplio margen de actuación para imponer con sus interpretaciones el único contenido constitucional válido.

ANUARIO DEL ÁREA SOCIO-JURÍDICA | MONTEVIDEO - URUGUAY | v. 10 | n. 1 | p. 32-49 | DEZ. 2018 
Por otra parte, dentro de la visión ideológica del constitucionalismo popular, es teóricamente tradicional una desconfianza hacia los jueces, en particular los de los tribunales constitucionales, por considerarlos una clara muestra de elitismo y de un poder al que se ha denominado contramayoritario.

Sobre este tema, tal vez la opinión más radical haya sido la del neozelandés Waldrom, quien cuestiona que el control de constitucionalidad sea un mecanismo de decisión apropiado para una sociedad democrática. En efecto, el autor pretende demostrar el carácter antidemocrático de la revisión judicial de constitucionalidad en cuanto afecta a cualquier sociedad democrática. Sus argumentos son esencialmente dos: el carácter no electivo de los jueces y el carácter político del debate sobre los derechos, en la medida en que en la mayor parte de los ciudadanos y los funcionarios públicos existe un compromiso respecto de los derechos fundamentales. El debate no es materia exclusiva de una interpretación jurídica ni formalista, sino que requiere un debate moral y político (Waldrom, 2006). Por su parte, Cárcova (2014) discrepa con Waldrom y sostiene, en lo medular, que resulta un argumento retórico tendencioso defender el carácter contramayoritario de la actividad de los jueces por sugerir que siempre actúan en contra de las mayorías, pues no es así; en todo caso, podría hablarse de un poder no mayoritario. En cuanto al proceso de elección de los magistrados, Cárcova estima que al intervenir los parlamentos - tanto al inicio como al final del proceso electivo - así como los otros poderes, la academia y las representaciones profesionales, se garantiza adecuadamente el proceso respectivo. Se instala entonces en el propio seno de la nueva visión latinoamericana una clara contradicción; los propios textos postulan la inapelabilidad y el carácter definitivo y vinculante de las decisiones de estos tribunales, en base a una interpretación auténtica y la elección con intervención ciudadana de los magistrados, lo que termina potenciando aquello de lo que se desconfía por contramayoritario.

Parece surgir así, con la intervención ciudadana para la elección de los magistrados, un intento de disminuir la tensión entre la ideología de la democracia popular radical y el control de constitucionalidad (Salazar Ugarte, 2012:380).

En suma, más allá de los méritos o deméritos que pueda tener la corriente que se analiza, es claro que esta se ha insertado en el escenario latinoamericano y no puede ser ignorada en su postulación innovadora.

Si bien puede admitirse que su novedad se encuentra más que nada en el rescate histórico de los conceptos de democracia popular radical, soberanía popular y poder constituyente, así como la protección constitucional inclusiva de grupos sociales vulnerables, no puede dejar de señalarse que hay muchos aspectos en los que ambas visiones de constitucionalismo coinciden. En efecto, cuestiones tales como $a$ ) la rigidez constitucional, $b$ ) el aspecto invasivo de las constituciones emergentes sobre todo el ordenamiento jurídico político, $c$ ) la incorporación positiva al texto constitucional de un abundante elenco de derechos previstos en la legislación ordinaria e incluso en tratados de derecho internacional, $d$ ) la justificación de la presencia textual de principios generales que luego serán claves para la interpretación e integración del texto constitucional y e) la aplicación de normas constitucionales respecto de la interpretación y aplicación de la ley son algunos de los temas que comparten ambas doctrinas.

No obstante, hay un tema al que ya se ha aludido y que adolece de cierta dificultad, o que al menos se presenta con flancos pasibles de críticas, particularmente en la nueva corriente latinoamericana: es el

ANUARIO DEL ÁREA SOCIO-JURÍDICA | MONTEVIDEO - URUGUAY | v. 10 | n. 1 | p. 32-49 | DEZ. 2018 
del papel adjudicado a los magistrados, incluyendo a los jueces de los tribunales constitucionales, y su forma de designación para ocupar tales cargos.

Es probable que en la versión eurocéntrica no existan demasiados reparos y autocuestionamientos al rol adjudicado a la Magistratura en todos sus niveles, sobre todo en lo que tiene que ver con la función de contralor sobre el sistema político; por el contrario, queda en evidencia que la nueva visión latinoamericana sufre en este aspecto alguna contradicción. En efecto, como ya se viera, como producto de la ideología que impregna la doctrina de la democracia popular radical, si bien se recela del poder elitista y contramayoritario que se atribuye a los magistrados, se culmina, a través del texto, potenciando su rol institucional al máximo al insertar modelos para su elección directa y popular, así como al otorgarle a su poder decisorio en la cuestión interpretativa de la Constitución el crédito de la inapelabilidad y su carácter vinculante.

Así las cosas, una adecuada perspectiva de este fenómeno constitucional revisionista permite inferir que, en muchos de sus aspectos, este resulta contradictorio además de complejo (Salazar Ugarte, 2012:286).

Además, este nuevo constitucionalismo obliga también a tener en cuenta que sobre el tablero existen dos distintas corrientes bien definidas y que, de alguna manera, si bien ambas responden a un tronco común democrático, han elegido, por las circunstancias históricas y políticas de sus respectivas gestaciones, distintos caminos o modelos de soluciones para los Estados potencialmente reclamantes o necesitados de ellas.

Todo esto requiere necesariamente de una prudente mirada de quienes se pongan en situación de interlocución frente a tales corrientes.

En relación con la cultura jurídica uruguaya, entendiendo por tal todos los mecanismos discursivos tradicionales de abordaje del derecho o, mejor aún, de la juridicidad (legislación, jurisprudencia, doctrina), e incluso aquellos no tradicionales (operatividad jurídica discursiva y pragmática gestada desde el imaginario social), el empuje constitucionalista ha entrado claramente en escena. Esto merece una aclaración.

En efecto, como pudo apreciarse en el análisis de determinados casos puntuales, la doctrina promovida por la versión neoconstitucionalista eurocéntrica ha tenido algunos momentos de irrupción en el campo decisional judicial uruguayo; ha sido recogida también, con las adaptaciones del caso, por una parte de la doctrina vernácula, tanto en el ámbito del derecho público como del privado.

No obstante, el apego generalizado de la Judicatura del país a una visión normativista del derecho hace que el tema pueda considerarse con clara excepcionalidad (Meliante, 2008:21, 46). ${ }^{9}$

Por otro lado, como se estableciera líneas arriba, el viraje hacia la constitucionalización del derecho implica también un cambio político en sentido estricto. En ese contexto, pese a la mera insinuación que de esta se ha hecho en el ámbito jurisdiccional y doctrinario, hace poco más de dos años fue considerada por la fuerza política que gobierna el país una revisión constitucional. Tal vez haya sido así no tanto por la incidencia que estos episodios jurisprudenciales y doctrinarios puedan haber tenido, sino por las necesidades políticas de adaptar el texto constitucional a la realidad o al signo de los tiempos, o, eventualmente, por ciertos cambios que puedan haber ocurrido en la matriz ideológica que sustenta las nuevas democracias latinoamericanas.

ANUARIO DEL ÁREA SOCIO-JURÍDICA | MONTEVIDEO - URUGUAY | v. 10 | n. 1 | p. 32-49 | DEZ. 2018 
En ese contexto, a través de la opinión de algunos legisladores nacionales, se pensó que esta debía comprender aspectos que fueran más allá de un mero cambio del sistema electoral e introducir también reformas en la parte dogmática de la Constitución, particularmente en lo relacionado con los derechos humanos, propiciando tanto la aplicación directa de los tratados internacionales que regulan este aspecto como la inclusión en el marco constitucional de situaciones tuteladas en leyes especiales, como por ejemplo, las de matrimonio igualitario y equidad de género.

En relación con la parte orgánica se planteó también la creación de un tribunal constitucional, lo que llevaría aparejada la necesidad de repensar el principio de separación de poderes en atención al modelo elegido a trasladar al sistema constitucional uruguayo. Trascendió también que uno de los modelos posibles para tomar como referencia para los cambios proyectados era el de la Constitución española vigente.

Lo cierto es que hoy todo esto quedó solo en meras y buenas intenciones; se ha dejado de hablar del tema por completo.

Si en algún momento se retomara el impulso reformista, con la prudencia con que este proceso debe ser tenido en cuenta en Uruguay, será necesario un diálogo cauteloso con ambas versiones del constitucionalismo contemporáneo. No considerar aquella gesta desde Latinoamérica constituiría una flagrante omisión, máxime en tanto se pretenda que la dignidad del ser humano deba constituirse en el centro de confluencia y la razón de ser del orden político y jurídico, en concordancia con los términos de resignificación del sujeto; y siempre, claro está, si esto se entendiera necesario - no debería ser de otra manera - en un escenario tan complejo como el que muestra Latinoamérica en la actualidad.

Sin perjuicio de ello, seguro que la puesta en escena de las distintas posibilidades que se han considerado y que provienen de matrices diferentes requerirá, antes de cualquier toma de decisión, la apertura de un debate público y amplio que la preceda —el más público y amplio que pueda instalarse- - y en el que intervengan legítimamente los poderes constituidos; pero también la Academia, los grupos sociales y los grupos de interés, transfiriendo su opinión a la ciudadanía para su conocimiento y análisis. Ello ayudará a buscar una salida correcta y también, sin duda, democrática.

\section{Conclusiones}

Como preámbulo, se estima procedente establecer que la perspectiva de análisis crítico en sentido estricto (Meliante, 2014:155-157) que sustentó el presente trabajo considera que el derecho debe ser pensado como un producto histórico, discursivo, positivo, público y social (Cárcova, 2007:162; Meliante, 2017:835). Así concebido, reclama como materia y escenario de intervención el conflicto y las contradicciones grupales dentro de las sociedades concretas, esto es, históricamente determinadas. Este protagonismo del derecho, como dice Cárcova, cumple una función paradojal: por un lado, da estabilidad al sistema, al formalizar y reproducir las relaciones sociales establecidas y reconducir, a su vez, formas de distribución del poder; por otro, en contextos democráticos, sirve también para transformar y remover las relaciones de poder en sentido progresivo. Es decir que cumple a la vez una función conservadora y otra

ANUARIO DEL ÁREA SOCIO-JURÍDICA | MONTEVIDEO - URUGUAY | v. 10 | n. 1 | p. 32-49 | DEZ. 2018 
transformadora. El poder se ve así como una situación estratégica en una sociedad determinada: donde hay poder hay resistencia. El papel del derecho dependerá así de una relación de fuerzas en el marco del conflicto social: «En manos de los grupos dominantes, constituye un mecanismo de preservación y de reconducción de sus intereses y finalidades; en manos de los grupos dominados, un mecanismo de defensa y contestación política» (Cárcova, 2007:139-140).

De esta manera puede ser procedente preguntarse si es que en realidad una mirada reductiva de lo que viene de analizarse estaría indicando, en última instancia, que el tema se resuelve en una reformulación de las formas de distribución del poder que con distintos matices se consolida socialmente, revelando con ello el grado de apertura democrática que cada sociedad presenta. Si el derecho es un instrumento del poder o si aquel es vulnerado por este; si se ha rendido alguna vez ante la espada (Ross) o si las relaciones entre derecho y poder responden a otro tipo de condiciones y características son temas del más alto nivel de consideración por parte de la filosofía jurídica.

Enmarcado en este contexto, es claro que el tema referido a las posibles formas que puede asumir un nuevo proceso de constitucionalización en Latinoamérica y particularmente en Uruguay desborda por su interés.

Dentro de esta perspectiva no puede existir una cultura jurídica que no tome en serio las constituciones (Ferraoli, 2002:20). Ello resulta imprescindible para restablecer, junto al significado de las palabras, el sentido mismo de la democracia y de sus garantías.

Se cierra entonces este conjunto de ideas pensando que el viraje del derecho hacia este proceso, ya se considere una nueva teoría general de él o una nueva teoría democrática de la Constitución, quebrando aun en este último caso el tríptico de la división tradicional de poderes, se presenta en el contexto de democratización en Latinoamérica con ciertos visos de novedad. El proceso y su dinámica contienen, como se dijo, respuestas para muchos de los aspectos que se han planteado en este trabajo. Como tal, debe ser examinado con prudencia, primero por una razón histórica y de circunstancia, y luego para estimar si es posible una definición clara y consistente de sus principales elementos constitutivos, con el objetivo de ayudar a profundizar la democracia en nuestro horizonte cultural.

En función de todo ello, como breves y provisionales conclusiones, procede establecer que:

1. En toda Latinoamérica, y se piensa que particularmente en la República Oriental del Uruguay, debe atenderse pronto, tanto en el discurso como en la praxis, al viraje que se ha producido hacia la constitucionalización del derecho y considerar para su análisis en profundidad el cambio de paradigma dogmático, jurídico y político que ello puede significar. Merece, pues, un estudio y un análisis prudente, pero a la vez racionalizado, ponderado, minucioso y sin prejuicios. En este contexto deberá tenerse en cuenta que este cambio provoca, ineludiblemente, la mutación de algunos de los aspectos estructurales más profundos del derecho, además de la gestación explícita e implícita de un nuevo concepto de Estado en el que resulta resquebrajada, de alguna manera, la linealidad del principio de separación de poderes propia del Estado de derecho en el sentido tradicional.

2. Resultaría provechoso, en particular para la filosofía del derecho y la teoría dogmática jurídica uruguaya, ámbito este último en que ya se inició un diálogo con el pensamiento

ANUARIO DEL ÁREA SOCIO-JURÍDICA | MONTEVIDEO - URUGUAY | v. 10 | n. 1 | p. 32-49 | DEZ. 2018 
neoconstitucionalista eurocéntrico, que este se inicie también con la nueva versión del nuevo constitucionalismo latinoamericano, teniendo plena conciencia de los aspectos contradictorios que pueda contener esta corriente y también el plexo de profundos avances y méritos que insinúa.

3. Debe quedar claro que en razón de lo anterior, el viraje hacia la constitucionalización del derecho implica también un cambio político en sentido estricto. En ese ámbito, se piensa que deben considerarse con suma atención algunas particularidades que se presentan como innovadoras y que han ocurrido en la matriz ideológica que sustenta la democracia latinoamericana, con más razón teniendo en cuenta que en Uruguay se consideró recientemente la posibilidad de una reforma constitucional integral.

4. Será necesario, por ende, que en forma previa a la toma de decisión con relación a la adopción de un modelo constitucional posible para Uruguay, con las particularidades inherentes a la formación social respectiva, se organice un amplio debate en el que se discutan en distintos ámbitos socioculturales la razones, alcances, méritos y deméritos del cambio que se proyecte, con la mayor difusión posible, y que el rol que de una manera u otra se perfila conferir a la Judicatura se discuta con claridad y rigurosidad.

5. Luego del debate que debe instalarse antes de tan prudente toma de decisión ciudadana, cuestión a la que se ha aludido en forma repetida, será necesario priorizar y por ende instalar constitucionalmente la perspectiva radical de que la dignidad del ser humano, en todos los aspectos posibles, quede constituida en el centro de confluencia y la razón de ser del orden político y jurídico; ello no es otra cosa que resignificar al sujeto despojándolo de ficciones en el complejo escenario que muestran las sociedades latinoamericanas hoy.

6. Por último, dejando de lado la importante y fecunda historia de la constitucionalización europea, en este trabajo se pretendió dar cuenta de las notas de un proceso que se inicia en Europa poco antes de que finalizara la primera mitad del siglo xx, pero que hoy, de cara al cuarto lustro del siglo XXI, se instala también con otros aires y como producto de otras tradiciones y connotaciones, en una sufrida y compleja Latinoamérica.

Vale la pena, pues, que todo esto se atienda sin ligereza.

\section{Bibliografía}

Burstin, D.; Sarlo, Ó. et al. (2010). La Constitución uruguaya: ¿rígida o flexible? Un estudio de teoría constitucional contemporánea, aplicado al caso uruguayo. Montevideo: Udelar, Facultad de Derecho.

Cárcova, C. M. (2007). Las teorías jurídicas post-positivistas. Buenos Aires: Lexis-Nexis.

- (2014). «Racionalidad formal o racionalidad hermenéutica para el derecho de las sociedades complejas». Congreso sobre Racionalidad Jurídica, Buenos Aires, octubre de 2014. Universidad de San Petersburgo, Universidad de Buenos Aires.

ANUARIO DEL ÁREA SOCIO-JURÍDICA | MONTEVIDEO - URUGUAY | v. 10 | n. 1 | p. 32-49 | DEZ. 2018 
Cobos, J. (1995). América Latina. Madrid: Acento Editorial.

Comanducci, P. (2002). «Formas de neoconstitucionlismo. Un análisis metateórico». Isonomía, Revista de Teoría y Filosofía del Derecho, 16 (abril), 90-102.

Durán Martínez, A. (2012). Neoconstitucionalismo y derecho administrativo. Montevideo: La Ley Uruguay.

Dworkin, R. (2012). Una cuestión de principios. Buenos Aires: Grupo Editorial Siglo Veintiuno.

Ferrajoli, L. (2002). «Uspositivismo crítico y democracia constitucional». Isonomía, Revista de Teoría y Filosofía del Derecho, 16 (abril), 7-20.

Gamarra, J. (2012). Neoconstitucionalismo, código y ley especial. Montevideo: Fundación de Cultura Universitaria.

Gargarella, R. y Courtis, C. (2009). El nuevo constitucionalismo americano: promesas e interrogantes. Santiago de Chile: Cepal. Recuperado de https://www.cepal.org/es/publicaciones/6162.

Guariglia, C. (2009). Presunción de constitucionalidad de las leyes. Montevideo: La Ley Uruguay.

Guastini, R. (2001). Estudios de teoría constitucional. Ciudad de México: Fontamara.

Leiza Zunino, P. (2016). El constitucionalismo del siglo XXI. Montevideo: La Ley Uruguay.

Luhmann, N. y Habermas, H. (1975). Discusión: teoría sobre los sistemas sociales. Barcelona: Barral.

Meliante, L. (2008). «La constitucionalización del derecho. El neoconstitucionalismo entre luces y sombras: su vinculación con la nueva teoría de la argumentación». Revista Crítica de Derecho Privado, 5, 21-46.

- (2014). «La crítica jurídica latinoamericana en sentido estricto: de la invisibilidad a su consideración en la doctrina nacional». Revista de la Facultad de Derecho, 36, 153-183.

- (2017). «Derecho, comunidades interpretativas y movimientos sociales: una fisura en la ortodoxia». Anales, 47 (año 14), 833- 863.

Noguera Fernández, A. (2011). «El neo-constitucionalismo andino: ¿una superación entre la democracia y la justicia constitucional?». Revista Vasca de Administración Pública, 90 (mayo-agosto), 167-196.

Nogueira de Alcalá, H. (2004). «Consideraciones sobre las sentencias de los tribunales constitucionales y sus efectos en América del Sur». Revista Iberoamericana de Derecho Procesal Constitucional, 2, 71 -104.

Salazar Ugarte, P. (2012). «El nuevo constitucionalismo americano (una perspectiva crítica)». En L. González Pérez y D. Valadés (comps.). Constitucionalismo contemporáneo: homenaje a Jorge Carpizo (345-387). Ciudad de México: Universidad Nacional Autónoma de México. Recuperado de https://archivos.juridicas.unam.mx/www/bjv/libros/7/3271/22.pdf.

Sagüés, N. (2006). «Las sentencias constitucionales exhortativas». Revista del Centro de Estudios Constitucionales, año 4, n. ${ }^{0}$ 2, vol. 4, 189-202. Recuperado de http://www.redalyc.org/articulo.oa?id=82040109.

Viciano Pastor, R. y Martínez Dalmau, R. (2010). «¿Se puede hablar de un nuevo constitucionalismo latinoamericano como corriente doctrinal sistematizada?». Ponencia presentada en el VIII Congreso Internacional de Derecho Constitucional, Ciudad de México. Valencia: Universitat de Valencia.

Waldrom, J. (2006). «The Core of the Case against Judicial Review». Yale Law Journal, 115, 1346-1406. Recuperado de https://www.jstor.org/stable/20455656. 


\section{Jurisprudencia citada}

Uruguay. Suprema Corte de Justicia Uruguaya. Sentencia 119, 8 de agosto de 2007. Leslie van Rompaey (redactor).

\section{Notas}

${ }^{1}$ La opinión, sin duda esquemáticamente expuesta, recoge las posiciones de Luhmann y Habermas (1975) sobre teoría de sistemas y otros tópicos.

2 El concepto de horizonte cultural es una categoría de análisis creada con definiciones propias lingüísticas, culturales (en mayor sentido), sociales e incluso antropológicas- que sirve para diferenciar, por ejemplo, el horizonte cultural latinomericano del norteamericano.

${ }^{3}$ A vía de ejemplo, Nogueira de Alcalá (2004) las tipifica en sentencias interpretativas, aditivas, sustitutivas, exhortativas, prospectivas y de omisiones legislativas. Por su parte, Sagüés (2006) utiliza el término sentencias manipulativas para clasificarlas en admisorias, desestimatorias, aditivas, sustitutivas y exhortativas (estas últimas llamadas también apelativas o con aviso).

4 Dworkin (2012), por ejemplo, expresa que en el Estado de derecho, por lo menos en la concepción que sostiene el autor, se «enriquece la democracia aportándole un foro de principios independientes, y esto es importante porque no solo se puede allí hacer justicia, sino porque el foro confirma que la justicia es, en última instancia, una cuestión de derechos individuales y no una cuestión independiente del bien público».

5 Artículos 60, 61, 62, 178 y 289 y siguientes de la Constitución boliviana.

6 Bolivia, Constitución de 2009, artículos 183 y 199; Ecuador, Constitución de 2008, artículo 434 (posibilidad de veeduría e impugnación ciudadana); Venezuela, Constitución de 1999, artículo 264 (posibilidad de objetar por parte de la ciudadanía).

7 Ver, por ejemplo: artículos 241 y 242 de la Constitución de Colombia de 1991; artículo 112 de la Ley Orgánica de la Corte Suprema de Justicia de Venezuela; artículo 439 de la Constitución de Ecuador de 2008, y artículo 120.1 de la Constitución de Bolivia de 2009.

8 Ecuador, Constitución de 2008, artículo 93 (acción de incumplimiento); Bolivia, Constitución de 2009, artículo 134.1 (acción de cumplimiento).

9 Ver sentencia de la Suprema Corte de Justicia uruguaya citada en la bibliografía, publicada en el Anuario de Derecho Civil Uruguayo, tomo xxxviII, Montevideo: Fundación de Cultura Universitaria, primer acto jurisdiccional de la Corte uruguaya que incursiona también en el tema. 